\title{
Influence of the Vertical Turbulent Exchange Parameterization on the Results of Reanalysis of the Black Sea Hydrophysical Fields
}

\author{
L. I. Sukhikh*, V. L. Dorofeyev
}

\author{
Marine Hydrophysical Institute, Russian Academy of Sciences, Sevastopol, Russian Federation \\ *e-mail: l.sukhikh@gmail.com
}

\begin{abstract}
Comparative analysis of two simulations of the Black Sea hydrophysical fields' long-term variability in 1993-2012 is performed. Two reanalyses are done using various methods of parametrizing the vertical turbulent exchange in the circulation model. The first variant implies a simple parameterization including the constant coefficient of vertical turbulent viscosity and the coefficient of vertical turbulent diffusion in a form of climatic profiles. The second simulation includes the turbulence model of the Mellor-Yamada type to parametrize the vertical exchange processes. Having been compared, the reanalysis results and the measurement data show that application of the turbulent model for parametrizing the vertical exchange yields a better description of the Black Sea water thermohaline structure. In particular, structure of the summer seasonal thermocline and location of the main halocline (in both of them maximum deviations of the model temperature and salinity from the in-situ measurement data are observed) are reproduced more accurately. Different methods of parametrizing the momentum vertical exchange influence the horizontal circulation vertical structure. The first variant of simulation shows that a significant part of the currents' kinetic energy is concentrated in the thin 10-m layer, and this fact affects the circulation features of shallow water on the northwestern shelf; whereas the simulation based on the turbulent model implies more intensive transfer of the kinetic energy to the lower layers. The carried out investigation shows that the results of the hydrophysical fields' reanalysis depend on accurate description of the thermodynamic processes in the sea upper layer and the vertical turbulent exchange ones, in particular.
\end{abstract}

Keywords: reanalysis, Black Sea dynamics, numerical modeling, data assimilation, thermohaline structure.

Acknowledgements: the investigation is carried out within the framework of the state task on the theme No. 0827-2018-0002 "Development of the methods of operational oceanology based on the inter-disciplinary studies of the marine environment formation and evolution processes, and mathematical modeling using the data of remote and direct measurements" (code "Operational oceanology") (numerical modeling with satellite data assimilation) under support of the RSF No.1777-30001 "New methods and supercomputer technologies of the World Ocean and Arctic basin nowcast and forecast" (analysis of the obtained results).

For citation: Sukhikh, L.I. and Dorofeyev, V.L., 2018. Influence of the vertical turbulent exchange parameterization on the results of reanalysis of the Black Sea hydrophysical fields. Physical Oceanography, [e-journal] 25(4), pp. 262-279. doi:10.22449/1573-160X-2018-4-262-279

DOI: 10.22449/1573-160X-2018-4-262-279

(C) 2018, L. I. Sukhikh, V. L. Dorofeyev

(C) 2018, Physical Oceanography

\section{Introduction}

In order to study the processes in the atmosphere, the World Ocean and the seas, the method of retrospective analysis (reanalysis) is widely used. One of the main advantages of the reanalysis is the possibility of obtaining long continuous spatial and temporal arrays of marine environment parameters. The analysis provides the investigation of the trends in the seasonal and interannual variability of the thermohaline characteristics and the kinetic energy of the current velocity for the whole basin, which is of scientific and practical interest. The reanalysis results 
are periodically updated based on the use of new or improved models, assimilation methods for measuring data and atmospheric effect parameters.

Thus, for the Black Sea a series of hydrophysical field reanalyses were carried out. They differed in the considered periods, circulation patterns and sets of measurement data assimilated in the models. In [1-3], the reanalysis was carried out on the basis of data assimilation of hydrological survey of temperature and salinity and covered the period from early 70s to early 90s. In [4, 5] the Black Sea dynamics over 20 years (1993-2012) was studied on the basis of satellite data assimilation. During these years, a small amount of hydrological survey was performed in the Black Sea, but remote sensing data such as sea level elevation anomalies and surface temperature became available.

The quality of physical reanalysis results depends on a number of factors: the applied circulation model, atmospheric effect that determines the boundary conditions on the sea surface and the assimilated measurement data. In [6] a study of reanalysis results sensitivity to the selection of atmospheric fields in the nearwater area for specifying the boundary conditions was performed. For this purpose two calculations were carried out, in which the same hydrodynamic model and similar data arrays for assimilation were used. Only the atmospheric effect fields determining the boundary conditions on the sea surface were different. Comparative analysis revealed that the results of two calculations are close to each other, i. e. the validity of the assimilated data is rather high. At the same time, a series of differences arising from different sets of atmospheric effect was identified.

As it was mentioned above, along with the assimilated data and atmospheric effect, the quality of performed physical reanalysis also depends on the applied hydrodynamic model. For correct reproduction of long-term evolution of the Black Sea hydrodynamics, which also includes both seasonal and interannual variability, high demands to the quality of the applied model are required. A number of circulation models that differ in their spatial resolution and methods for describing hydrodynamic processes, including the parameterization of vertical turbulent fluxes of heat, momentum, and salt, were developed for the Black Sea. In addition to the models used in the abovementioned reanalyses, we should mention the numerical experiments described in other works aimed at simulating the dynamics of the entire basin of the Black and Azov Seas and its separate regions, including the ones with the measurement data assimilation [7-12].

The purpose of the present work is to study the dependence of the Black Sea hydrophysical field reanalysis results on the selection of vertical turbulent exchange parameterization method which plays an important role when modeling the processes in the sea upper layer.

\section{Research method}

To solve the problem, the reanalysis of the Black Sea hydrophysical fields (1993-2012) on the basis of circulation model variant previously used in [4] was performed. For more accurate description of thermodynamic processes in the active sea layer, especially the vertical exchange processes, a turbulent model was added to the abovementioned circulation one. 
The Black Sea circulation model was developed in Marine Hydrophysical Institute [13] to describe the large-scale variability of the Black Sea basin dynamic characteristics. Later, this z-level model based on approximation of a system of primitive ocean dynamics equations was modified and used in current nowcast forecast system of the Black Sea hydrophysical model [14].

Spatial step of the model used in this work is $4.8 \mathrm{~km}$ which provides rather accurate description of synoptic processes. The model contains 40 vertical computational levels condensing towards the sea surface. Time step was $5 \mathrm{~min}$. An optical model for calculating the penetrating short-wave radiation was included to the circulation model. For the parameterization of vertical fluxes of momentum, heat and salt, a turbulent model is used. This is a QETE quasi-equilibrium turbulent energy model [15], which is part of the Mellor-Yamada models family [16] and consists of two equations -turbulent energy evolution $q^{2} / 2$ and the turbulence scale l. This variant of circulation model was described in detail in [17] and was applied for the modeling of the Black Sea long-term dynamics evolution with no data assimilation.

At side boundaries in the places of river estuaries and straits the values of normal velocity component (different from zero) were set as boundary conditions. They were determined by climatic values of water discharge. The velocity of lower Bosphorus current in the described calculations had a constant value which provided total water balance over the considered period (the discharge of rivers and straits, evaporation and precipitation). In the river estuaries at the computational area boundary low salinity values (3\%) were set, and in the lower Bosphorus current - the salinity value (36\%) corresponding to the Mediterranean Sea water. At rigid boundaries of the computational area the salt fluxes were equal to zero. Heat fluxes at side boundaries were assumed to be equal to zero.

At upper undisturbed sea boundary for the equations of circulation model and turbulent one the atmosphere parameters obtained by the results of ERA-Interim (European Center for Medium-range Weather Forecasts) atmosphere reanalysis [18] are used as boundary conditions.

For assimilation in the circulation model remote sensing data were used: sea surface temperature (SST) and anomalies of free surface elevation. Moreover, at the horizons below $200 \mathrm{~m}$ average temperature and salinity values at a given horizon were corrected according to annual average temperature and salinity profiles on which climate seasonal variation was imposed. Annual average temperature and salinity profiles were prepared by V.N. Belokopytov according to the results of hydrologic survey carried out that year and drifter data. Sea surface temperature for 1993-2009 period was taken from GHRSST and NODC archive. For the latest reanalysis period (2010-2012) the SST data were taken from OSI TAC archive. For assimilating the data on sea level anomaly all available satellite altimetry data over the reanalysis period from NASA, AVISO and SL TAC archives were used. Assimilation procedures in this work completely correspond to the ones applied before in [4]. These methods are based on optimal interpolation and relaxation of model fields to the existing measurement data.

The obtained results were compared with the reanalysis performed by the model containing 35 computational levels. In this model vertical turbulent 
diffusion was parameterized by the coefficients depending on the depth and time, and vertical viscosity - by a constant coefficient of turbulent viscosity [4, 5].

In what follows, for brevity, we will denote reanalysis, the results of which are described in $[4,5]$, as $\mathrm{P} 1$, and reanalysis in the circulation model into which a turbulent model is added, as P2.

\section{The analysis of results}

We consider the characteristics of the Black Sea thermohaline structure, velocities of currents and kinetic energy obtained using two circulation models.

Temperature. Let us carry out the analysis of temperature regime of the Black Sea upper layer according to the results of two calculations. The difference of temperatures in different layers of the Black Sea (Fig. 1, $a-d$ ) has a pronounced interseasonal variability. Interannual variability is also noticeable, especially in two lower layers. Sea surface temperature (Fig. 1, a) from P1 calculation, as a rule, is higher at the end of the year and at the beginning of the next one. The duration of periods with positive values of the temperature difference is about 3 months. In the remaining seasons, the temperature for P2 calculation is higher for all years. The maximum values of negative deviations are always observed in the middle of summer. It should be noted that in both calculations the SST assimilation is carried out. However, the assimilated satellite data have gaps caused by cloudiness, therefore the surface temperature values obtained in two calculations by different models do not coincide.

The curve for the variability of the temperature difference in 0-30 m layer (Fig. $1, b$ ) is qualitatively close to the temperature behavior at the surface. The difference between them consists in the occurrence of additional peaks for periods with both positive and negative values of the temperature difference throughout the year. The range of fluctuations significantly varies from year to year. The maximum fluctuation range for the difference of temperatures at the surface and in the upper $30-\mathrm{m}$ layer reaches $1^{\circ} \mathrm{C}$. Just like at the sea surface, the maximum difference in 0-30 m layer is observed in summer when the water temperature in this layer is higher according to P2 calculation. This fact is confirmed by the graphs of the temperature climatic profiles for August (Fig. 1, e), where the summer thermocline (the middle of which is located at about $20 \mathrm{~m}$ depth) is situated deeper according to the calculation of $\mathrm{P} 2$.

In 30-100 $\mathrm{m}$ layer there is other character of temperature differences distribution (Fig. 1, c). Annual average temperatures are, in general, higher for P1 calculation, except for several years. The maximum deviations for the periods with negative values of temperature differences are observed at the beginning of the year. During the summer season, the water temperature in this layer in P1 calculation is either higher, or close to the temperature from P2 calculation. It is known that cold intermediate layer (CIL) is mainly located in 30-100 m layer in the Black Sea and its waters are renewed during the winter season [19, 20]. According to the performed analysis, in winter the temperature of surface waters is lower in P2 calculation and, correspondingly, in spring and summer the CIL temperature will be lower for this calculation. In 100-200 m layer (Fig. 1, $d$ ) water temperature in $\mathrm{P} 1$ calculation is always lower than in $\mathrm{P} 2$. 

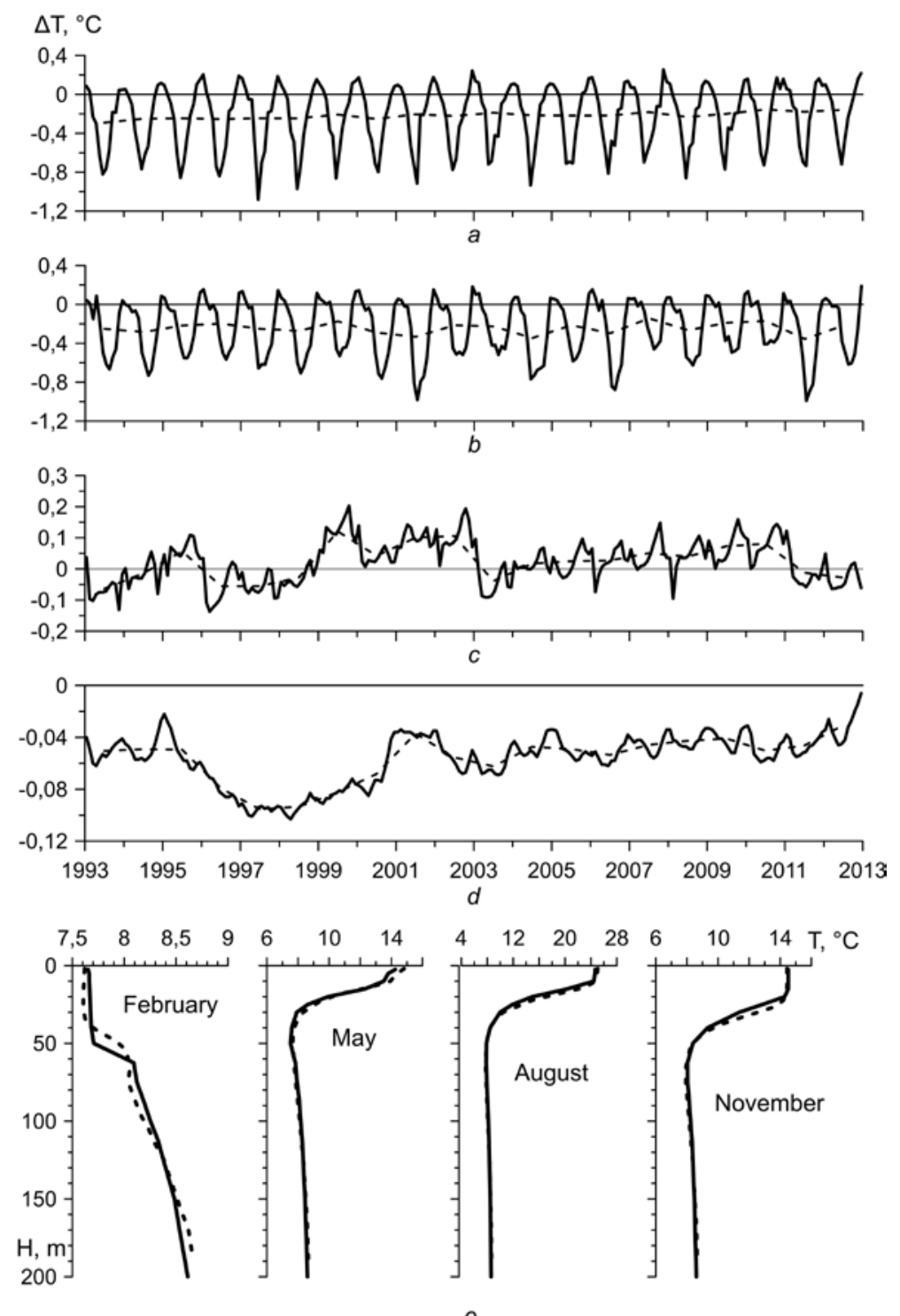

Fig. 1. Evolution of the monthly average (solid lines) temperature differences (averaged over the basin area) (P1-P2) on the sea surface and in the layers 0-30, 30-100 and 100-200 m ( $a-d$ ), respectively, (dash lines denote the annual average temperature differences); the temperature climatic profiles for four months (solid lines correspond to P1 calculation and dashed lines - to P2 calculation) (e)

According to the climatic profiles (Fig. 1, e), in February the temperature from P2 calculation is lower down to $40 \mathrm{~m}$ depth. In spring and summer, when the heating takes place, water temperature near the sea surface is higher for P2 calculation. In autumn and winter, when the cooling occurs, water temperature the sea surface from P1 calculation is higher. It means that heating and cooling processes in the sea upper layer occur faster in P2 calculation as a result of more intensive vertical mixing processes. Moreover, in August and November seasonal thermocline from P2 calculation is located lower. 
For more detailed illustration of seasonal temperature variation in the upper $200 \mathrm{~m}$ layer we consider the diagrams of monthly average climatic temperature distributions and their differences (Fig. 2, $a-c$ ). In these diagrams it can be seen that in P2 calculation the CIL core looks more powerful, it is located deeper and remains longer in time. In the diagram of differences this is manifested in the fact that the temperature from P2 calculation is lower during the entire year at the depth corresponding to the CIL core. Below $130 \mathrm{~m}$ it is always higher. In the upper 50-m layer the water temperature from P1 calculation is usually lower. The maximum values of negative deviations are located at 20-30 m depth in summer-autumn season. As it was mentioned above, this is related with the fact that seasonal thermocline from P2 calculation is located lower.
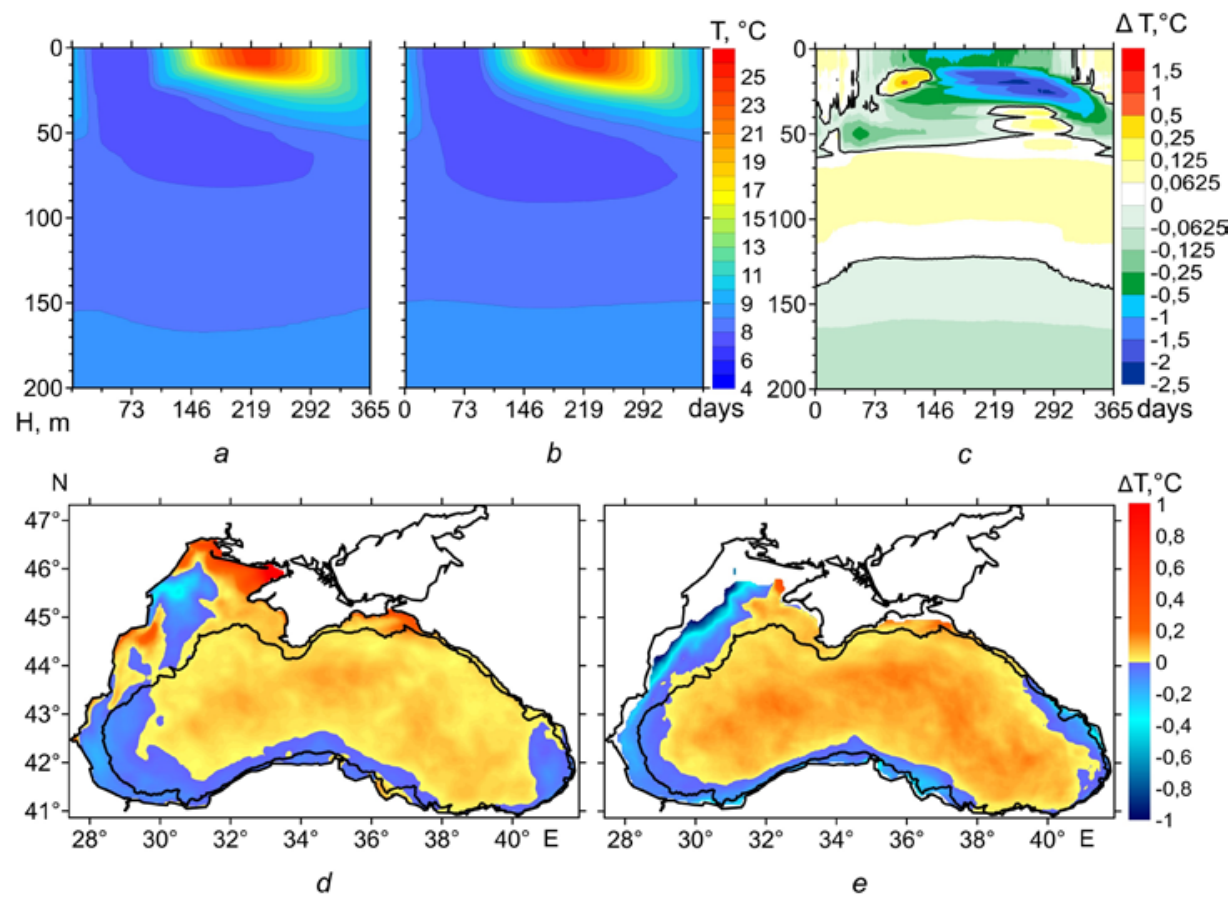

Fig. 2. Temporal evolution of the averaged over the basin area monthly average temperature values in the upper $200 \mathrm{~m}$ layer based on the reanalyses P1 (a) and P2 (b), and their difference (P1-P2) (c); the charts of the monthly average climatic distributions of temperature difference (P1-P2) on the sea surface $(d)$ and in the $0-30$ m layer $(e)$ for February

The examples of maps of temperature difference spatial distribution obtained according to the results of two calculations are given in Fig. 2, $d, e$. At both horizons average over the area temperature difference is positive but at northwestern shelf near the Danube mouth the temperature from P1 calculation is lower. Further, this negative anomaly extends along the entire western and eastern coasts of the Black Sea.

It was assumed above that higher (in general) temperature in 30-100 m layer is associated with weaker CIL from P1 calculation. The quantitative characteristic of CIL can be average thickness over its area. In Fig. 3 annual average values of CIL 
thickness are represented. The CIL thickness in each point of the grid was calculated as a distance between the upper and lower isotherms of $8^{\circ} \mathrm{C}$. If the sea surface temperature was below $8^{\circ} \mathrm{C}$ (winter season) then the distance was measured from the surface. Then the average values over the basin area were determined and on their basis - annual average values. These values significantly change from year to year. The range of fluctuations is almost $60 \mathrm{~m}$ for both calculations. Annual average values of CIL thickness according to P2 calculation are higher for all years of the period under consideration, which proves the temperature behavior in 30100 m layer (Fig. 1, c). The correlation of CIL thickness with winter sea surface temperature is also can be seen in the graphs: the lower is winter temperature, the thicker is CIL, and vice versa.

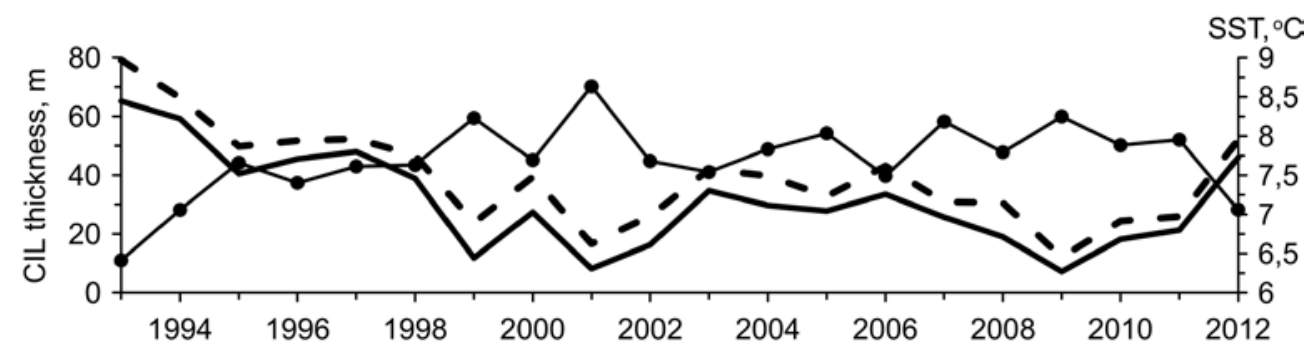

Fig. 3. Annual average values of the cold intermediate layer thickness based on the results of two reanalyses (solid lines correspond to simulation P1 and dash lines - to P2 calculation), and winteraverage sea surface temperature (line with circles)

Salinity. The structure of salinity fields in the Black Sea upper layer is formed by a series of factors: a flux of fresh water through the free surface and in the areas of river runoffs, as well as the water exchange through the straits. Taking into account the fact that atmospheric effect fields and river discharges in the both considered calculations were the same, we may assume that in the formation of salinity fields, other things being equal, the circulation, both horizontal and vertical, is decisive.

In order to analyze the differences in the salinity fields we are to consider, as well as for the temperature fields, monthly averaged values and annual average ones.

At the surface, in 0-30 and 30-100 m layers (Fig. 4, $a-c$ ) annual average salinity values from P1 calculation are higher for all the years, while in 100-200 m layer they are always lower (Fig. 4, d). This means that the main halocline in P2 calculation is sharper than in P1. In the seasonal variability the greatest difference in subsurface layer (Fig. 4, $a, b$ ) is observed at the beginning of the year when average salinity value from P1 calculation exceeds the corresponding one from P2 by $0.1 \%$ and higher. In summer season surface salinity in P1 calculation is lower and in entire 0-30 m layer it is usually higher, while the difference reaches the maximum. In 30$100 \mathrm{~m}$ layer the maximum of difference is observed at the end of the year, minimum - in spring. In 100-200 m layer seasonal variability is poorly manifested. As it can be seen in Fig. 4, $e$, in the upper 200m layer the salinity from P1 calculation is for all seasons down to the depth of about $120 \mathrm{~m}$, except for $50 \mathrm{~m}$ horizon in February. 

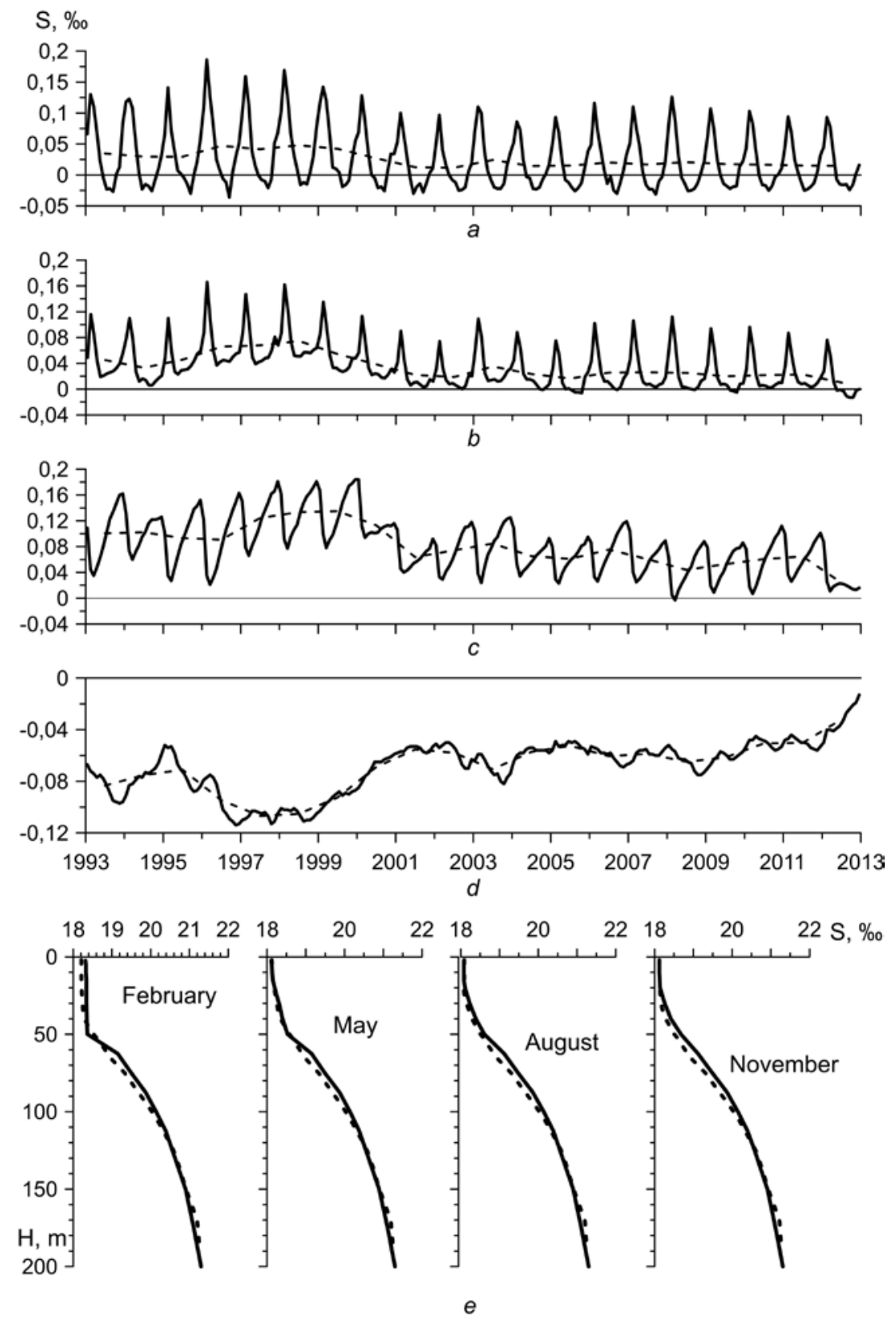

Fig. 4. The same as in Fig. 1, for salinity

Another illustration of seasonal variability in the upper $200 \mathrm{~m}$ layer of the Black Sea are time diagrams of climatic seasonal variation of salinity according to the data of P1 and P2 reanalyses, as well as a difference between them (Fig. 5, $a-$ c). Minimum salinity of surface waters is observed at the beginning of summer after the spring flood of the rivers that inflow into the Black Sea basin. After this value salinity values begin to grow and reach their maximum in early winter which corresponds to the general understandings of the Black Sea thermohaline structure. 
In the diagram of the salinity difference it can be seen that in summer on the surface and at $0-20 \mathrm{~m}$ depth the salinity is higher by P2 calculation. Negative deviations are also detected at $50 \mathrm{~m}$ depth during the winter season. Then, down to approximately $125 \mathrm{~m}$ depth according to P1 calculation salinity is higher for all seasons. The maximum positive deviations are recorded in the layer with a center at $65 \mathrm{~m}$ horizon, which corresponds to the halocline position depth. Thus, the determination of halocline position has significant effect on the accuracy of obtaining results.
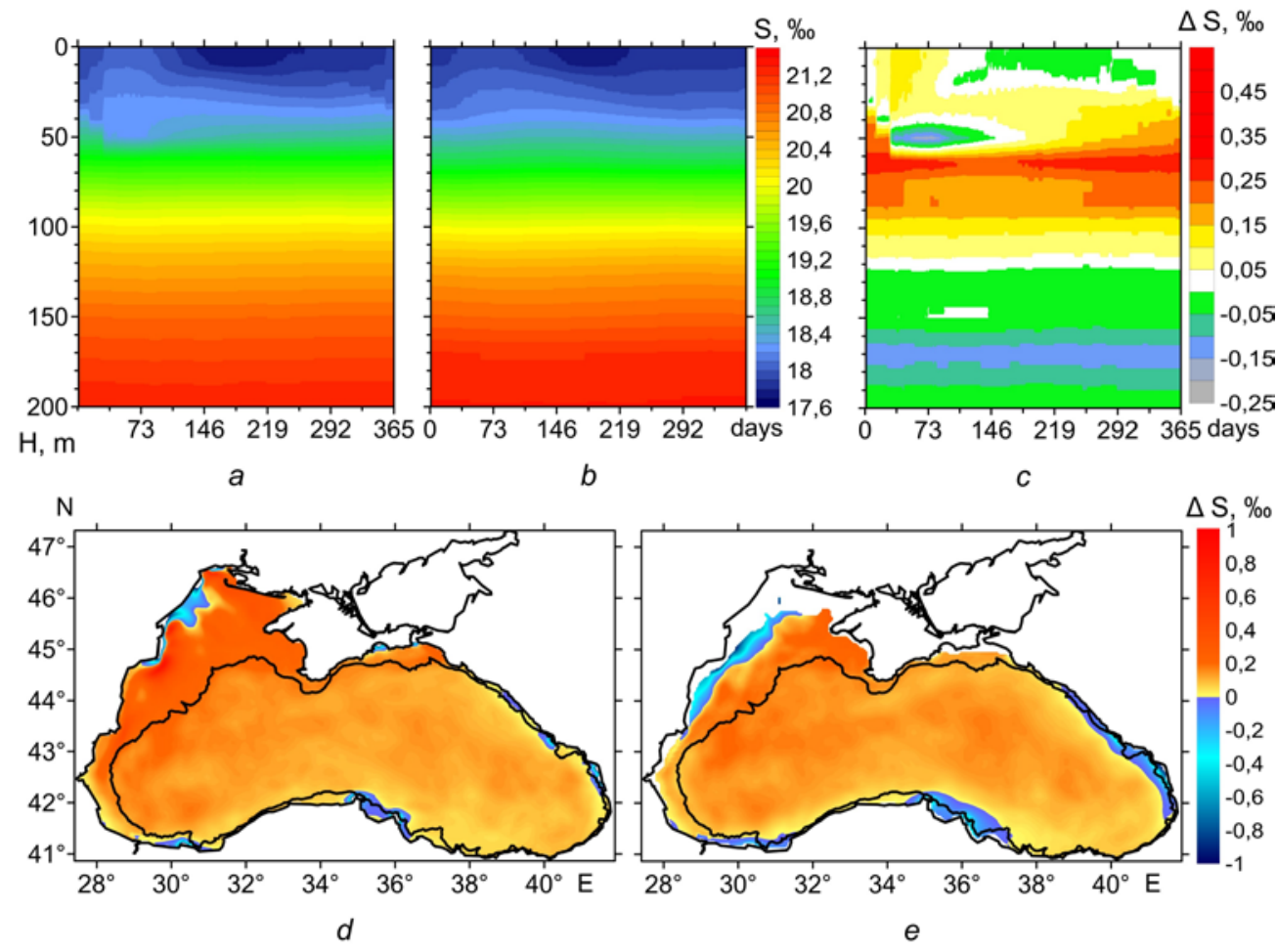

Fig. 5. The same as on Fig. 2, for salinity

Spatial distribution of salinity value difference at the sea surface and on $30 \mathrm{~m}$ horizon (Fig. $5, d, e$ ) shows that (except for the river estuaries) salinity is higher by P1 calculation. These results correspond to the graphs in Fig. 4, $a, b$.

Circulation. The main element of circulation in the upper layer of the Black sea is the Rim Current (RC). It encircles the sea along the continental slope and forms a large-scale cyclonic gyre. In winter, the main cycle is divided into two cycles of a smaller scale in the western and eastern parts of the basin [21-23]. In addition to the Black Sea Rim Current, it is observed an intensive synoptic variability that distorts simple structure of the cycles: for example, intensive meandering of the RC occurs, on the right from the jet quasi-stationary mesoscale anticyclones, which (in statistical sense) are the elements of seasonal cycle, appear [24-26]. 

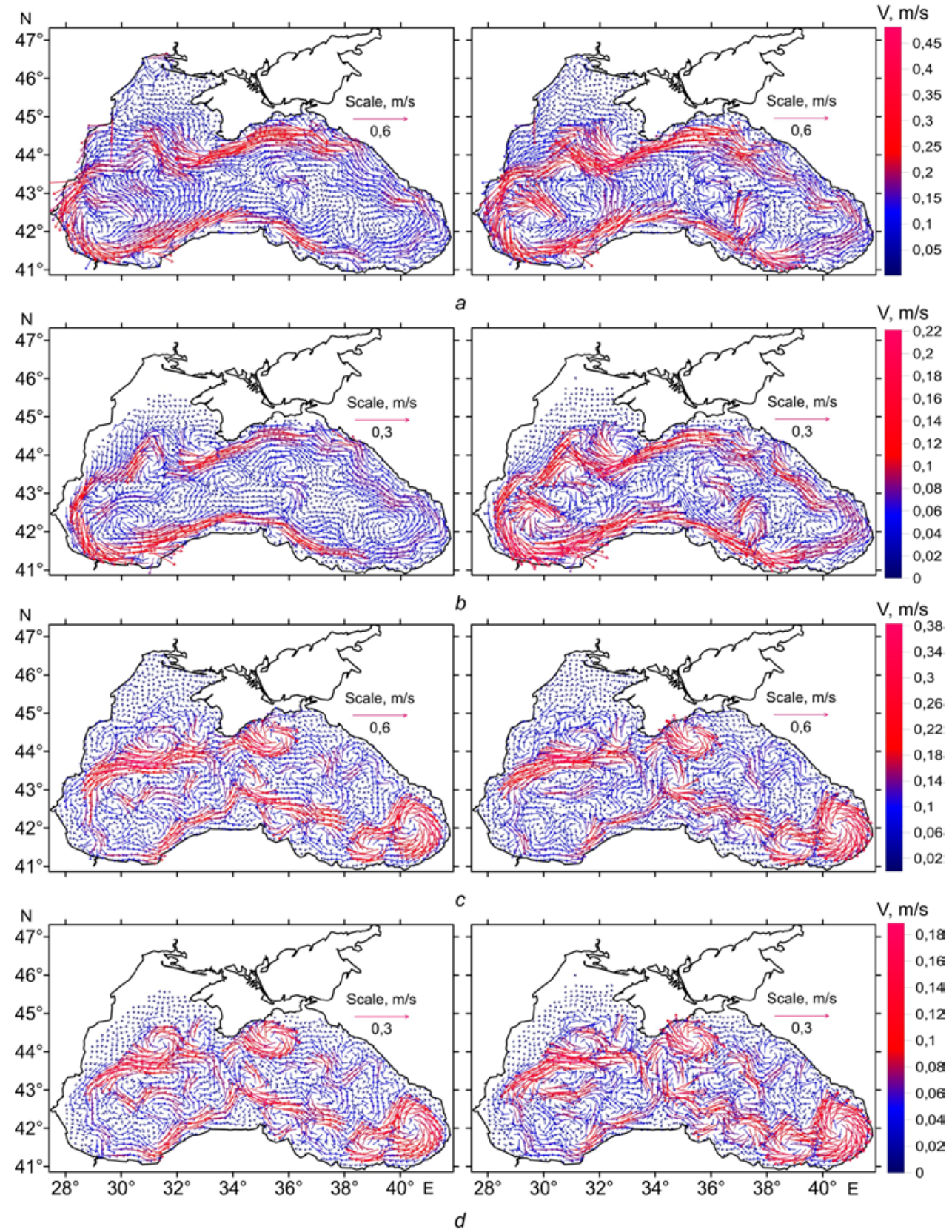

Fig. 6. Charts of the Black Sea mean currents in the upper $30 \mathrm{~m}$ layer $(a)$ and in the $30-100 \mathrm{~m}$ layer (b) for January 15, 1995 and for July 15, 2011 (c), (d). To the left - the results of reanalysis P1, to the right - the results of reanalysis P2

As examples of two-dimensional circulation in the sea upper layer, the maps of currents for winter and summer, obtained according to the results of two calculations, are represented in Fig. 6. On the map for January 15, 1995 (Fig. 6, $a$, b) more intensive circulation according to P2 model in both considered layers, when the RC features and eddy structures are well-manifested, is observed. In $30 \mathrm{~m}$ 
surface layer significant differences are observed in north-eastern and southwestern parts of the Black Sea. The Black Sea Rim Current also remains in 30$100 \mathrm{~m}$ layer according to the results of two models. However, in this layer the differences are more obvious than in the upper layer. By the results of P2, the currents are much more intensive.

Circulation patter for July 15, 2011 (Fig. 6, c, d) is typical for summer - the pronounce RC jet is absent, separated eddy structures are observed. Batumi anticyclone is one of the largest formations. As it can be seen, in the sea upper layer the circulations are very close according to both calculations. In 30-100 m layer they are also similar but the circulation obtained from P2 calculation is significantly stronger. Moreover, in P2 the chain of anticyclones along the south-eastern Black Sea coast is more pronounced.

Cyclonic character of the Black Sea upper layer circulation is mainly determined by positive value of vertical component of the wind field vorticity above the region. Since in both calculations the same fields of atmospheric effect (including the wind field) were used as boundary conditions on the sea surface and the same altimetry data were assimilated, the differences in circulation by the results of two reanalyses can be due only to the properties of the applied model.

For a quantitative comparison of the results for horizontal circulation we consider the behavior of the monthly average density of the kinetic energy of currents (averaged over the basin area) in the upper 30-m layer and in 30-100 m one according to two reanalyses, as well as their difference.

Interannual and interseasonal variability of kinetic energy density is representted in the graphs in Fig. 7, $a-d$. From year to year the range of fluctuations can differ by times. The maximum values are observed in winter season. The intensity of currents in deeper layer is weaker than in the surface one. In the sea surface layer kinetic energy density is mainly higher according to P2 calculation. Exceptions are the winters of 2003 and 2006 and the summer of 1997. In 30-100 m layer kinetic energy density is higher according to P2 reanalysis in all years and seasons (except for the winter of 2006).

For more detailed analysis of current intensity dependence on the depth we consider the profiles of kinetic energy density distribution for different seasons (Fig. $7, e$ ). The profiles are constructed on the basis of monthly average climatic values of velocity by averaging over the basin area.

According to the given graphs, kinetic energy density by the results of P1 significantly exceeds the corresponding values of P2 in the upper 10-m layer for all seasons except for a spring. Down to the depth of approximately $100 \mathrm{~m}$ kinetic energy of currents from P2 calculation is higher (see Fig. 6). Below $100 \mathrm{~m}$ depth kinetic energy becomes small, while it is higher by P1 calculation. Thus, we can say that in upper $100 \mathrm{~m}$ sea layer kinetic energy density is distributed more uniformly by the depth in P2 calculation. As is known, kinetic energy of currents is mainly generated by the wind at the sea surface. In P1 calculation its significant part is concentrated in thin 10 m layer, while in P2 calculation it is transferred to the lower layers more intensively. Such difference in kinetic energy density variation with depth is explained by the applied vertical exchange models. In P2 the momentum flux from the surface to the deeper layers is more intensive than in P1 calculation due to the use of Mellor - Yamada type model. 


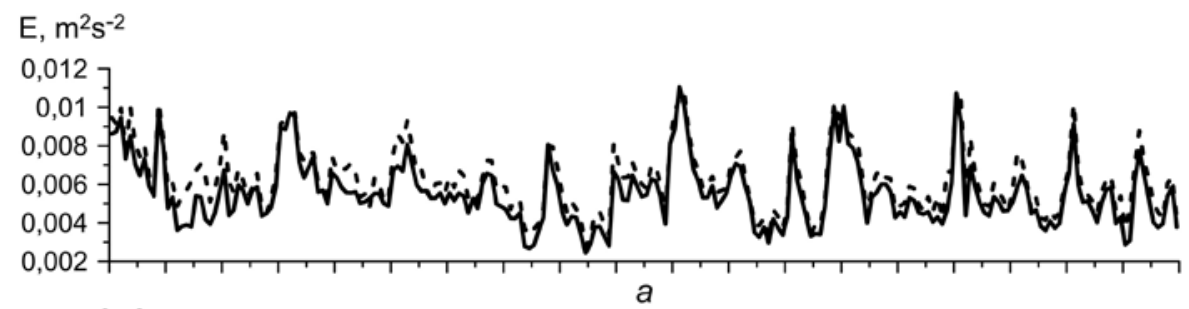

$\Delta \mathrm{E}, \mathrm{m}^{2} \mathrm{~s}^{-2}$

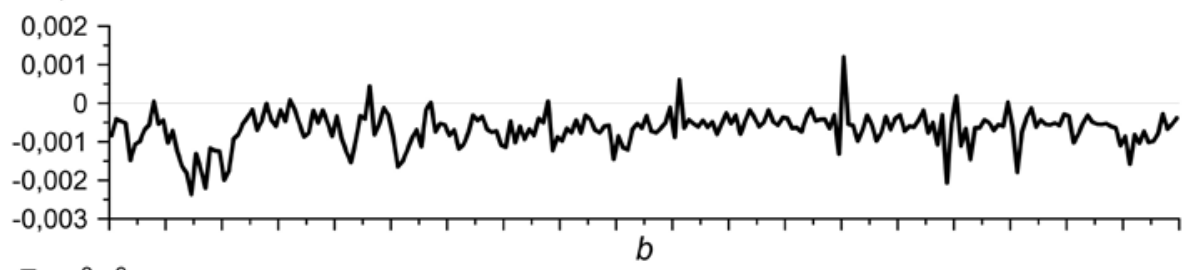

$\mathrm{E}, \mathrm{m}^{2} \mathrm{~s}^{-2}$

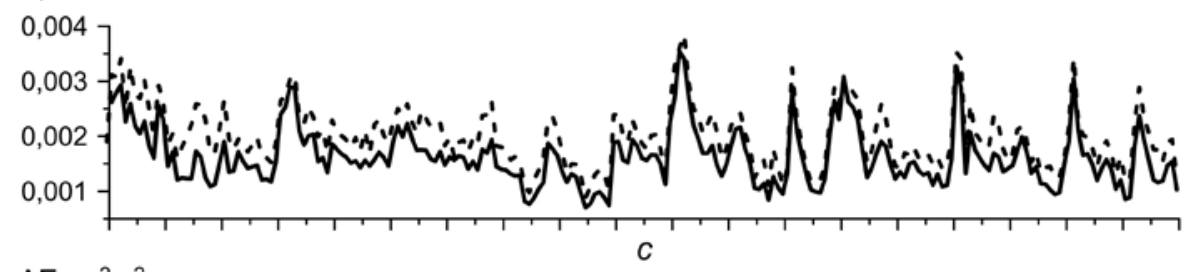

$\Delta \mathrm{E}, \mathrm{m}^{2} \mathrm{~s}^{-2}$
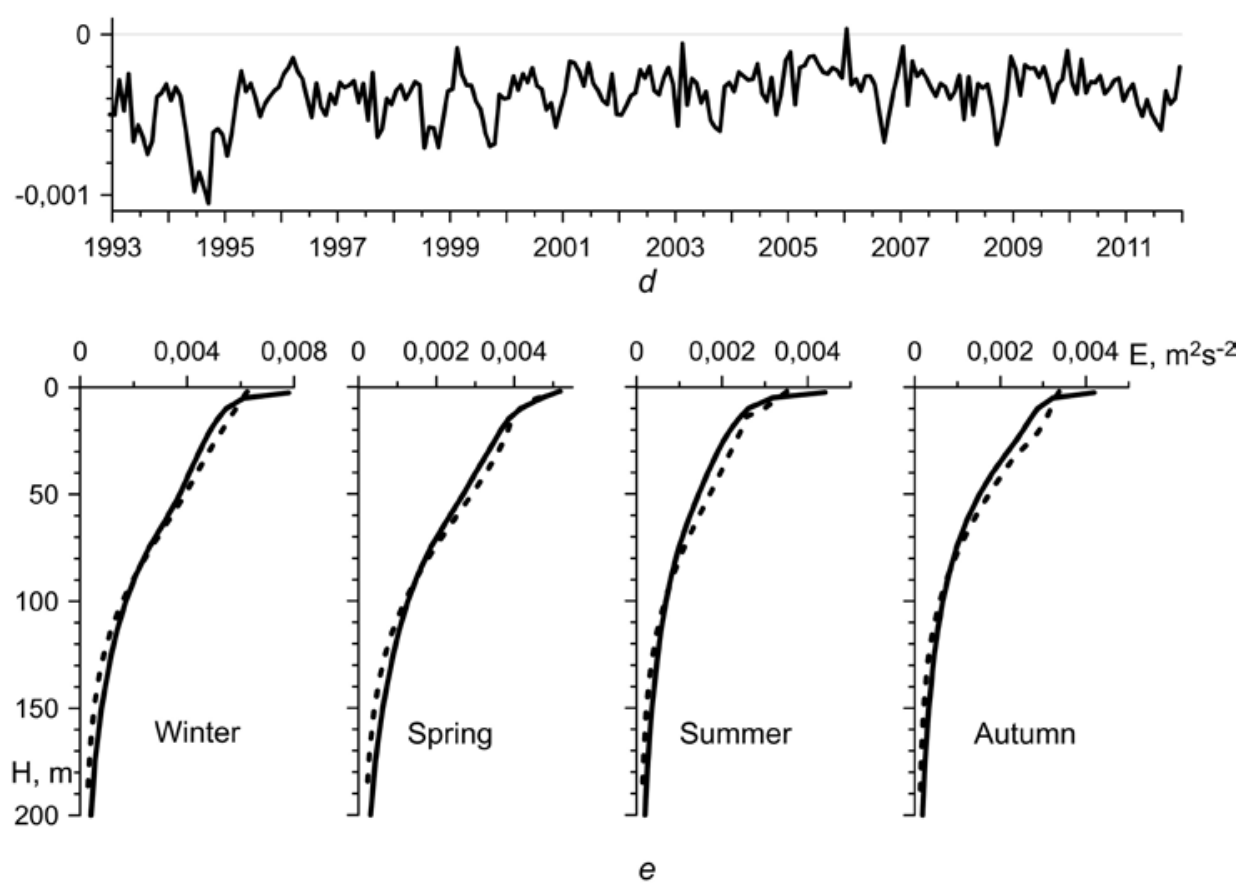

Fig. 7. Evolution of the averaged over the basin area monthly average kinetic energy density of currents in the layers $0-30 \mathrm{~m}(a)$ and 30-100 $\mathrm{m}(c)$; difference between the kinetic energy densities of currents (P1-P2) in the layers 0-30 m (b) and 30-100 m (d); climatic profiles of the kinetic energy density $(e)$. Solid lines on the fragments $a, c$ and $e$ correspond to P1 calculation, and dashed lines - to P2 calculation 


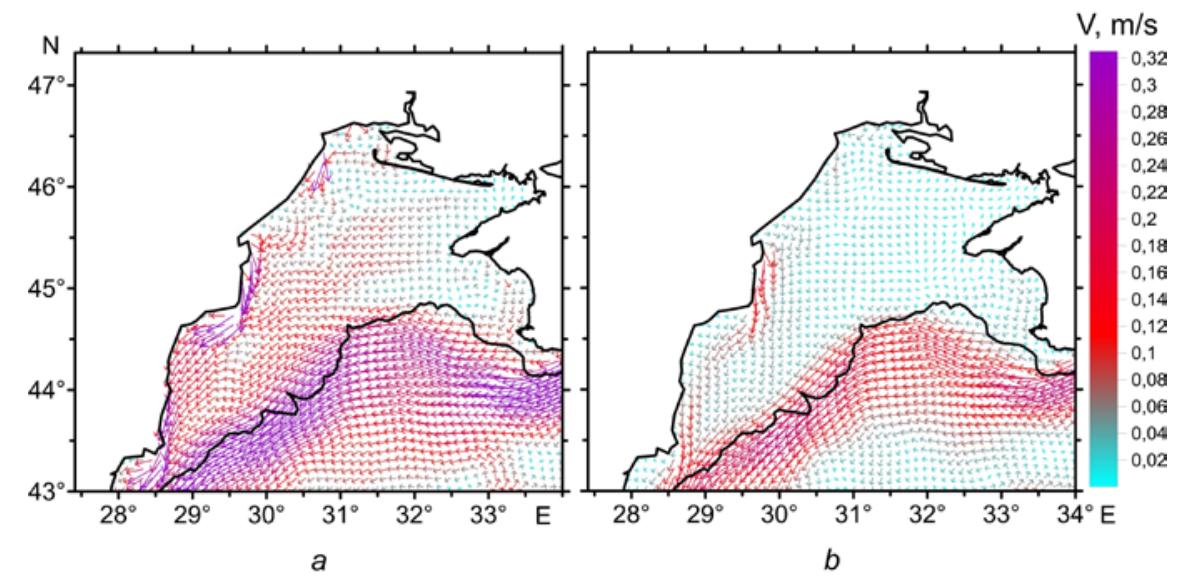

Fig. 8. Charts of climatic monthly average current velocities in the upper layer of the northwestern shelf in the Black Sea based on the reanalyses P1 (a) and P2 (b)

Higher kinetic energy density in thin surface layer in P1 calculation affects the features of circulations at a shallow-water part of the north-western shelf (NWS). In Fig. 8 the fragments of monthly average climatic circulation at the NWS in February for two considered calculations are given. The RC jet is stronger at these fragments than in P1 calculation. Moreover, in this calculation at the NWS a surface current directed to the south-west and forming rather intensive alongshore current can be noticed. This current transports the water from the shelf into the deepwater part of the basin where it is taken by the RC and transferred further. In P2 calculation this current is also observed, but it is significantly weaker. The existence of such current explains a configuration of the area of negative differences of temperatures in Fig. 2, $d, e$. Cold surface water from the shelf is spreading more intensively along the western and partly the southern coast of the Black Sea in P1 calculation. This also explains the range of negative salinity values at the upper horizons (Figure 5, $d, e$ ), although the salinity distribution in the coastal zone is also affected by the parameterization of the fresh water runoff at the places of river inflow, which somewhat differs for these calculations.

\section{Comparison with the data of observations}

The data of hydrographic measurements allow one to carry out the validation of numerical modeling results. To assess the quality of the reanalysis products obtained in [4], temperature and salinity measurements performed in the Black Sea since 1993 were used. In the present work we carried out the same validation of the results of P2 calculations and compared them with the previously obtained ones. The fields of temperature and salinity obtained by the modeling results were interpolated with respect to space and time in those points and time moments in which the measured profiles were. After this, average profiles of mean and rootmean-square deviations of modeling results from the measurements were constructed for each season and for entire array.

The profiles of temperature model value deviations from the measured ones for both calculations are shown in Fig. 9, $a$. In winter the highest deviations are 
observed at approximately $50 \mathrm{~m}$ depth. Root-mean-square deviations are similar for both calculations and systematic error is higher for P2 calculation. The difference between the measured and model values is also noticeable in $0-10 \mathrm{~m}$ surface layer. This error must be caused by the fact that in winter season satellite measurements have numerous gaps due to the cloudiness and, correspondingly, the effect surface temperature assimilation is insignificant.
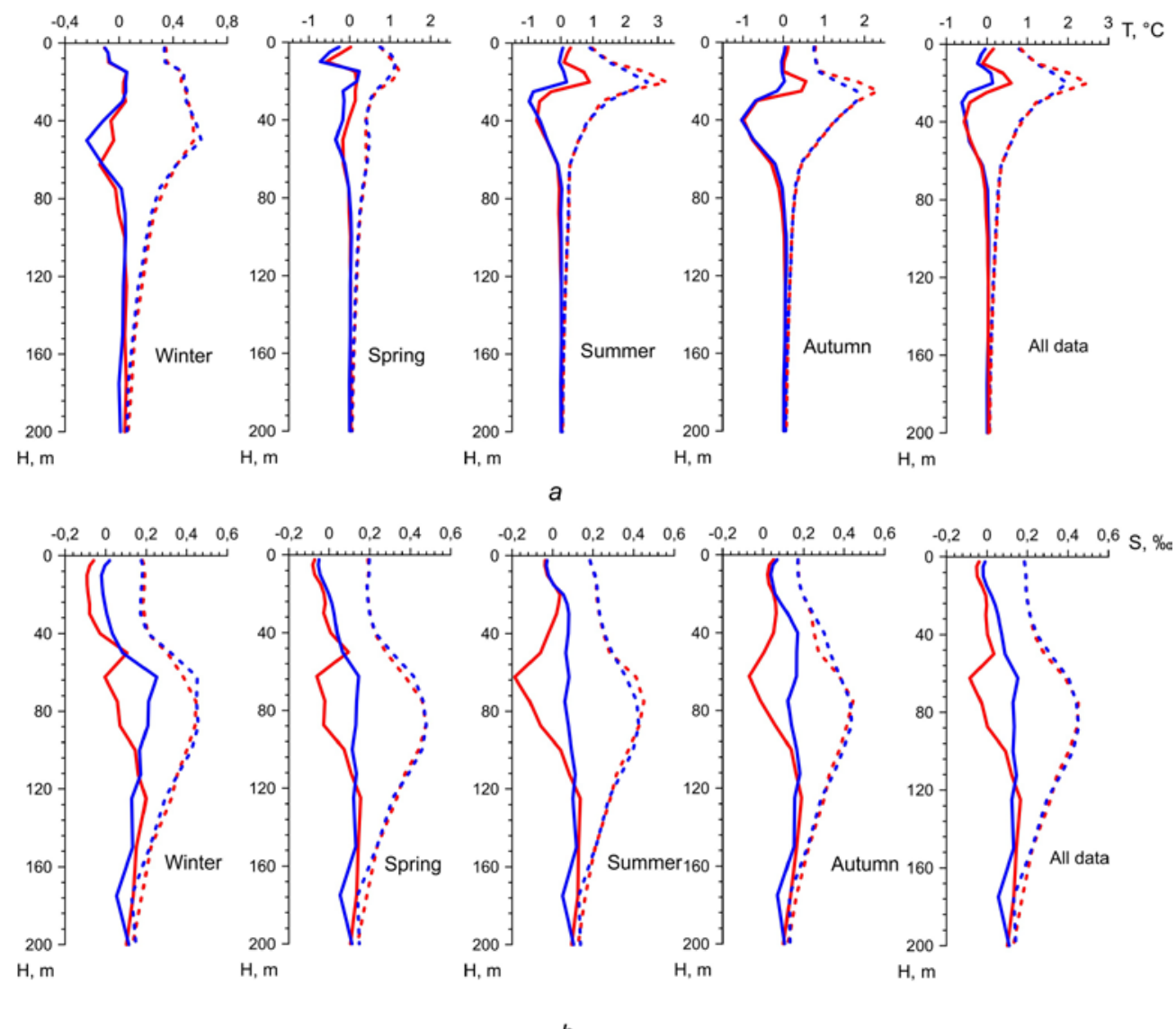

Fig. 9. Average (solid lines) and root-mean-square (dash lines) deviations of the measurement data from the results of reanalyses P1 (red curves) and P2 (blue curves) for temperature ( $a$ ) and salinity (b)

In summer and autumn the greatest deviations in both calculations are observed at 20-30 m depths corresponding to the seasonal thermocline location. The highest temperature gradients are noted there. Therefore, even a small error in the depth determination results in significant error in temperature value. Nevertheless, P2 calculation provides lower root-mean-square and systematic errors, i. e. in this case the model reproduces seasonal thermocline location more accurately. Significant difference of measured temperature from the model one is also observed in these seasons in 30-60 m layer, which approximately corresponds to the CIL location. This indicates the fact that water temperature in in the CIL is 
according to the reanalyses results somewhat higher than according to the ones of the measurements.

If we consider the behavior of mean and root-mean-square deviation profiles obtained over the entire data array, then we can say that the greatest deviations are observed at $25 \mathrm{~m}$ depth, which corresponds to the position of the summer seasonal thermocline. The error in temperature determination from P2 calculation is smaller than in P1. Apparently, this is due to higher vertical resolution in the circulation model and the use of the turbulent model to describe vertical exchange processes.

The maximum root-mean-square deviations between the measured and model salinity fields for both calculations are observed in all seasons within 50-100 m layer. It corresponds to the depth of halocline location which is an area of the most significant natural variability of salinity field as the maximum vertical gradients are observed there (Fig. 9, b). The maximum root-mean-square deviations reach $0.4 \%$. Near the sea surface root-mean-square deviations are $0.2 \%$ for the both calculations. Systematic error in P2 calculation is insignificant and is far lower than in P1, except for the winter season when model salinity is lower than the measured one from approximately $50 \mathrm{~m}$ depth. In P1 calculation the greatest systematic error is determined at approximately $65 \mathrm{~m}$ depth corresponding to the location of the main halocline center. In general, the salinity values obtained from P2 calculation are in better agreement with the data of observations. This indicates that P2 model describes the Black Sea water salinity vertical structure more accurately.

\section{Conclusion}

A comparison of the results of two reanalyses of the Black Sea hydrophysical fields over 1993-2012 obtained using different variants of circulation model was carried out in this work. When performing the calculations, the data of ERAInterim atmospheric reanalysis were chosen as boundary conditions at the sea surface. Assimilation data and the algorithms of their assimilation were similar, the methods of parameterization of vertical exchange processes and the model vertical resolution were different. In P1 calculation rather simple parameterization with constant coefficient of vertical turbulent viscosity and vertical turbulent diffusion coefficient in the form of climatic profiles was applied. In P2 calculation a turbulent model of Mellor - Yamada model type was used to parameterize the vertical exchange processes. Thus, an impact of a selection of vertical exchange process method on the obtained results of the Black Sea hydrophysical field reanalyses was studied in this work.

A comparison with hydrographic measurement data revealed that the results of P2 calculation describe the thermohaline structure of the Black Sea waters better. Particularly, they reproduce with the structure of summer seasonal thermocline, in which the maximum deviations of model values from in-situ measurements are observed, with higher accuracy. The main halocline position is also reproduced better.

The temperature in the layer where the CIL is located is somewhat higher according to the results of both calculations than according to measurement data. 
At the same time, average CIL thickness is higher according to P2 which corresponds to greater sea surface temperature from P1 calculation in winter season when the renewal of CIL waters takes place.

The character of the Black Sea surface water circulation has some differences for two calculations. According to the maps of currents, the circulation from P2 calculation is more intensive in both winter and summer periods except for thin $10 \mathrm{~m}$ near-surface layer. This fact affects the behavior of kinetic energy density.

Thus, the use of circulation model with higher vertical resolution and parameterization of vertical exchange processes by the turbulent model provided more accurate reproduction of the main features of thermohaline structure and water circulation trend of the Black Sea.

\section{REFERENCES}

1. Knysh, V.V., Kubryakov, A.I., Moiseenko, V.A., Belokopytov, V.N. and Inyushina, N.V., 2008. Tendentsii v Izmenchivosti Termokhalinnykh i Dinamicheskikh Kharakteristik Chernogo Morya, Vydelennye po Rezul'tatam Reanaliza za Period 1985-1994 [Trends in the Black Sea Thermohaline and Dynamic Variability Defined by the Results of Reanalysis for 1985-1994 Years Period]. In: MHI, 2008. Ekologicheskaya Bezopasnost' Pribrezhnoy i Shel'fovoy Zon i Kompleksnoe Ispol'zovanie Resursov Shel'fa [Ecological Safety of Coastal and Shelf Zones and Comprehensive Use of Shelf Resources]. Sevastopol: MHI. Iss. 16, pp. 279-290 (in Russian).

2. Knysh, V.V., Korotaev, G.K., Moiseenko, V.A., Kubryakov A.I., Belokopytov V.N. and Inyushina, N.V., 2011. Seasonal and Interannual Variability of Black Sea Hydrophysical Fields Reconstructed from 1971-1993 Reanalysis Data. Izvestiya, Atmospheric and Oceanic Physics, [e-journal] 47(3), pp. 399-411. https://doi.org/10.1134/S000143381103008X

3. Knysh, V.V., Korotaev, G.K., Mizyuk, A.I. and Sarkisyan, A.S., 2012. Assimilation of Hydrological Observation Data for Calculating Currents in Seas and Oceans. Izvestiya, Atmospheric and Oceanic Physics, [e-journal] 48(1), pp. 57-73. https://doi.org/10.1134/S0001433812010057

4. Dorofeev, V.L. and Sukhikh, L.I., 2017. Study of Long-Term Variability of Black Sea Dynamics on the Basis of Circulation Model Assimilation of Remote Measurements. Izvestiya, Atmospheric and Oceanic Physics, [e-journal] 53(2), pp. 224-232. doi:10.1134/S0001433817020025

5. Dorofeev, V.L. and Sukhikh, L.I., 2016. Analysis of Variability of the Black Sea Hydrophysical Fields in 1993-2012 Based on the Reanalysis Results. Physical Oceanography, [e-journal] (1), pp. 33-47. doi:10.22449/1573-160X-2016-1-33-47

6. Sukhikh, L.I. and Dorofeyev, V.L. 2016. The Study of Sensitivity of the Black Sea Hydrophysical Fields Reanalysis Results to the Applied Atmospheric Forcing. Physical Oceanography, [e-journal] (5), pp. 45-60. doi:10.22449/1573-160X-2016-5-45-60

7. Staneva, J.V., Dietrich, D.E., Stanev, E.V. and Bowman, M.G., 2001. Rim Current and Coastal Eddy Mechanisms in an Eddy-Resolving Black Sea General Circulation Model. Journal of Marine Systems, [e-journal] 31(1-3), pp. 137-157. doi:10.1016/S0924-7963(01)00050-1

8. Zalesny, V.B., Gusev, A.V. and Moshonkin, S.N., 2013. Numerical Model of the Hydrodynamics of the Black Sea and the Sea of Azov with Variational Initialization of Temperature and Salinity. Izvestiya, Atmospheric and Oceanic Physics, [e-journal] 49(6), pp.642-658. doi:10.1134/S0001433813060133

9. Zalesnyi, V.B., Gusev, A.V. and Agoshkov, V.I., 2016. Modeling Black Sea Circulation with High Resolution in the Coastal Zone. Izvestiya, Atmospheric and Oceanic Physics, [e-journal] 52(3), pp. 277-293. doi:10.7868/S0002351516030147 
10. Agoshkov, V.I., Parmuzin, E.I. and Shutyaev, V.P., 2013. Observational Data Assimilation in the Problem of Black Sea Circulation and Sensitivity Analysis of its Solution. Izvestiya, Atmospheric and Oceanic Physics, [e-journal] 49(6), pp. 592-602. doi:10.7868/S0002351513060023

11. Diansky, N.A., Fomin, V.V., Zhokhova, N.V. and Korshenko, A.N., 2013. Simulations of Currents and Pollution Transport in the Coastal Waters of Big Sochi. Izvestiya, Atmospheric and Oceanic Physics, [e-journal] 49(6), pp. 611-621. doi:10.1134/S0001433813060042

12. Kordzadze, A.A. and Demetrashvili, D.I., 2013. Short-Range Forecast of Hydrophysical Fields in the Eastern Part of the Black Sea. Izvestiya, Atmospheric and Oceanic Physics, [e-journal] 49(6), pp. 674-685. doi:10.1134/S0001433813060091

13. Demyshev, S.G. and Korotaev, G.K., 1992. Chislennaya Energosbalansirovannaya Model' Baroklinnykh Techeniy Okeana s Nerovnym Dnom na Setke C [Numerical Energy-Balanced Model of Baroclinic Currents in the Ocean with Bottom Topography on the C-Grid]. In: IVM RAN, 1992. Chislennye Modeli i Rezul'taty Kalibrovochnykh Raschetov Techeniy v Atlanticheskom Okeane [Numerical Models and the Results of Calibrating Currents in the Atlantic Ocean], Moscow: IVM RAN, pp. 163-231 (in Russian).

14. Korotaev, G.K., Oguz, T., Dorofeyev, V.L., Demyshev, S.G., Kubryakov, A.I. and Ratner, Yu.B., 2011. Development of Black Sea Nowcasting and Forecasting System. Ocean Science, [e-journal] 7(5), pp. 629-649. https://doi.org/10.5194/os-7-629-2011

15. Galperin, B., Kantha, L.H., Hassid, S. and Rosati, A., 1988. A Quasi-Equilibrium Turbulent Energy Model for Geophysical Flows. Journal of the Atmospheric Sciences, [e-journal] 45(1), pp. 55-62. https://doi.org/10.1175/1520-0469(1988)045<0055:AQETEM>2.0.CO;2

16. Mellor, G.L. and Yamada, T., 1982. Development of a Turbulence Closure Model for Geophysical Fluid Problems. Reviews of Geophysics, [e-journal] 20(4), pp. 851-875. doi:10.1029/RG020i004p00851

17. Dorofeyev, V.L. and Sukhikh, L.I., 2017. Modeling of Long-Term Evolution of Hydrophysical Fields of the Black Sea. Oceanology, [e-journal] 57(6), pp. 784-796. doi:10.1134/S0001437017060017

18. Dee, D.P., Uppala, S.M., Simmons, A.J., Berrisford, P., Poli, P., Kobayashi, S., Andrae, U., Balmaseda, M.A. and Balsamo, G. [et al.], 2011. The ERA-Interim Reanalysis: Configuration and Performance of the Data Assimilation System. Quarterly Journal of the Royal Meteorological Society, [e-journal] 137(656), pp. 553-597. doi:10.1002/qj.828

19. Ovchinnikov, I.M. and Popov, Yu.I., 1984. K Voprosu o Formirovanii Kholodnogo Promezhutochnogo Sloya v Chernom More [On the Formation of the Cold Intermediate Layer in the Black Sea]. Doklady of the Academy of Sciences of the USSR. Earth Science Sections, 279(4), pp. 986-989 (in Russian).

20. Gertman, I.F., 1991. Termohalinnaya Struktura Vod Morey [Thermohaline Structure of Sea Water]. In: A.I. Simonov \& E.N. Altman eds., 1991. Gidrometeorologiya i Gidrokhimiya Morey SSSR. 1991. T. IV. Chernoe More. Vyp. 1. Gidrometeorologicheskie Usloviya [Hydrometeorology and Hydrochemistry of the USSR seas. The Black Sea. Iss. 1. Hydrometeorological Conditions]. Saint Petersburg: Gidrometeoizdat, pp. 146-195 (in Russian).

21. Nelepo, B.A. ed., 1980. Kompleksnye Okeanograficheskie Issledovaniya Chernogo Morya [Complex Oceanographic Studies of the Black Sea]. Kiev: Naukova dumka, 240 p. (in Russian).

22. Nelepo, B.A. ed., 1984. Izmenchivost Gidrofizicheskih Poley Chernogo Morya [Variability of Hydrophysical Fields of the Black Sea]. Leningrad: Gidrometeoizdat, 240 p. (in Russian).

23. Simonov, A.I. and Altman, E.N. eds., 1991. Gidrometeorologiya i Gidrokhimiya Morey SSSR. 1991. T. IV. Chernoe More. Vyp. 1. Gidrometeorologicheskie Usloviya [Hydrometeorology and Hydrochemistry of the USSR seas. Vol. IV. The Black Sea. Iss. 1. Hydrometeorological Conditions]. Saint Petersburg: Gidrometeoizdat, 4(1), 429 p. (in Russian).

24. Oguz, T. and Besiktepe, S., 1999. Observations on the Rim Current sSructure, CIW Formation and Transport in the wlWestern Black Sea. Deep Sea Research, [e-journal] 46(10), pp. 1733-1753. https://doi.org/10.1016/S0967-0637(99)00028-X 
25. Korotaev, G., Oguz, T., Nikiforov, A. and Koblinsky, C., 2003. Seasonal, Interannual, and Mesoscale Variability of the Black Sea Upper Layer Circulation Derived from Altimeter Data. Journal of Geophysical Research, [e-journal] 108(C4), pp. 3122. https://doi.org/10.1029/2002JC001508

26. Zhurbas, V.M., Zatsepin, A.G., Grigor'eva, Yu.V., Eremeev, V.N., Kremenetsky, V.V., Motyzhev, S.V., Poyarkov, S.G., Poulain, P.-M., Stanichny, S.V. and Soloviev, D.M., 2004. Water Circulation and Characteristics of Currents of Different Scales in the Upper Layer of the Black Sea from Drifter Data. Oceanology, 44(1), pp. 30-43.

About the authors:

Larisa I. Sukhikh - Junior Research Associate, Department of the Ocean Processes Dynamics, FSBSI MHI (2 Kapitanskaya Str., Sevastopol, 299011, Russian Federation), SPIN-code: 6168-6090, ORCID ID: 0000-0002-8002-4891, ResearcherID: M-4381-2018, l.sukhikh@gmail.com

Viktor L. Dorofeev - Senior Research Associate, Department of the Ocean Processes Dynamics, FSBSI MHI (2 Kapitanskaya Str., Sevastopol, 299011, Russian Federation), Ph.D. (Phys.Math.), SPIN-code: 7144-1950, ORCID ID: 0000-0001-7979-8235, ResearcherID: G-1050-2014, viktor.dorofeev@mhi-ras.ru

Contribution of the co-authors:

Larisa I. Sukhikh - carrying out the numerical calculations, analysis of the obtained results

Viktor L. Dorofeev - statement of the problem, carrying out the numerical calculations, analysis of the obtained results

All the authors have read and approved the final manuscript.

The authors declare that they have no conflict of interest. 